\title{
SUSTAINABLE BLENDED TEACHING PRACTICES: LESSONS LEARNED FROM INSTRUCTOR PERSPECTIVES
}

\author{
Pavani Vemuri ${ }^{1}$, Stephan Poelmans ${ }^{1}$, Veerle van Rompaey ${ }^{1}$, Yi-Shan Tsai ${ }^{2}$, Mark Brown ${ }^{3}$ \\ and Dragan Gasevic ${ }^{2}$ \\ ${ }^{1}$ KU Leuven, 3000 Leuven, Belgium \\ ${ }^{2}$ Monash University, 3800 Clayton, Australia \\ ${ }^{3}$ Dublin City University, 9 Dublin, Ireland
}

\begin{abstract}
The higher education (HE) sector has undergone drastic changes due to the preventive measures needed to cope with the Covid-19 pandemic since March 2020. As a result, most traditional classroom teaching had to move to synchronous or asynchronous online instruction. In the post-Covid-19 era, institutions will, at least partially, go back to teaching in person, and blended teaching (BT) practices will conceivably become the true norm. Although BT practices have been employed and researched extensively over the past two decades, a deeper or more extensive blending of courses will still be a major switch for many teachers and students. More than ever, it is vital for instructors not just to understand how to blend but also to understand the evolution of BT practices and the choices made to arrive at sustainable practices that positively impact the learning experience. In this article, the authors aim to elaborate on the contexts which stimulate or provide a catalyst for the use and subsequent growth of sustainable BT practices in HE. A mixed approach of inductive and deductive thematic analysis is used to analyze 26 interviews of instructors, considered either as pioneers or experienced BT adopters in six HE institutions across Europe (Belgium, Denmark, Finland, Ireland, Netherlands, UK). This preliminary analysis revealed that the identified over-arching themes, the drivers and enablers that promote BT, are dynamic in nature and vary in diverse contexts. This study can give insights into BT adoption and help instructors and institutions improve planning or (re)design of courses into successful and sustainable BT practices.
\end{abstract}

\section{KEYWORDS}

Blended Teaching Practices, Drivers, Enablers, Instructor Perspectives, Blended Education, Blended Learning

\section{INTRODUCTION \& MOTIVATION}

Over the past decade, Blended Teaching (BT) has been considered as a significant educational trend (e.g., Dziuban, et al 2018; Dziuban, Shea \& Moskal 2020). BT practices have been used to achieve different purposes. BT increases learning outside the traditional face-to-face classroom settings and can have a positive impact on student motivation, engagement (Ibrahim \& Nat 2019) and learning performance (Lu et al. 2019). While a vast number of studies on the usefulness of blended learning (BL) already exist, discussions of BT approaches and their maturity and sustainability are quite rare.

There is still a need to better investigate the alignment of pedagogy and the use of educational technologies (Castro 2019) and understand the contexts in which BL can result in the best possible learning outcomes (Porter \& Graham 2016). Ibrahim and Nat (2019) suggest a need for research in considering factors motivating instructors to integrate $\mathrm{BL}$ in their courses. While switching to $\mathrm{BL}$ in a HE setting, the literature describes numerous challenges: resistance to change, lack of sufficient pedagogical models or BL policies (Porter \& Graham 2016), and lack of interest, time, or staff to engage in BT (Smith \& Hill 2019).

More than ever, higher education (HE) institutions are exploring different BL formats. It is vital for instructors to understand how to blend and understand the possible choices to be made to arrive at sustainable BT practices. In this article, the authors aim to elaborate on the contexts which stimulate the use and subsequent growth of sustainable, successful, and mature BT practices in HE. In particular, we want to 
understand which enabler(s) and driver(s) can explain the instructor's choices for using BT approaches. The research questions can be stated as follows:

RQ1. Which enabler(s) and driver(s) influence an instructor's choice of using BT approaches?

RQ2. Do enabler(s) and driver(s) change with subsequent iterations of a course taught using BT approaches?

In order to do this, a mixed approach of inductive and deductive thematic analysis is used to extract information from interviews of instructors, teaching teams or course designers. This study can give insights into BT adoption and help instructors and institutions improve planning or (re)design of their respective courses into successful and sustainable BT practices.

\section{LITERATURE}

Blended learning is defined as "learning as a result of a deliberate, integrated combination of online and face-to-face learning activities. Instruction encompasses activities which the educators organize and implement deliberately, in order for learners to be able to achieve stated educational objectives" (van Valkenburg 2020). In recent years, a growing number of literature reviews, meta-analyses and empirical studies have been published on the following topics on and for the success of BT practices: BL design (e.g., Boelens, De Wever, Voet 2017); consequences and adoption of BL with student perceptions and attitudes; learning outcomes and completion rates; challenges for tutors and learners (e.g., Rasheed, Kamsin \& Abdullah, 2020; Müller \& Mildenberger 2021, etc.); focus on the implementation, adoption, and maturity of BL approaches internationally (such as Porter et al. 2016; Marshall, 2010; Goeman et al 2021); those that have considered such factors as motivations, drivers, enablers, and incentives (Laurillard 2014; Ibrahim \& Nat 2019). Some studies discuss perceived barriers to successful integration of technology (Bingimlas 2009; Lawrence and Tar, 2018; Mercader and Gairin 2020). Other previous studies that conducted thematic analysis (Lam 2015; King \& Cerrone Arnold 2012) either had limited scope or focused on impact and/or challenges in only one domain or discussed a small sample of practices not necessarily mature or sustainable.

There exists a gap in the literature in studying sustainable BT practices and the factors that lead instructors to adopt BT and persistently use and revisit their BT approaches (per each course run), enhancing the quality and maturity of their BT practices. Laurillard (2014) in her vision paper of BT, mentions several drivers and enablers and states 'updating educational drivers and enablers to keep pace with the digital world could be sustainable and progressive over the long term, and would make innovation affordable as a natural part of how institutions operate'. In our study, we look for evidence and dive deeper into the connections and the core issues that drive and enable instructors to adopt and continue using BT and in diverse educational contexts.

\section{PROJECT AND METHODOLOGY}

As a part of a European Erasmus+ project, to develop the European Maturity model for Blended EDucation (EMBED, https://embed.eadtu.eu/), the partners identified 32 diverse BT practices (at participating universities); both at course and program levels. They were sustainable either in using innovative design $\&$ tool of BE practice or had several iterations (maturity) of the BL course. A semi-structured questionnaire was used for the interviews which were recorded, transcribed and translated to English if necessary. To understand instructor perspectives, the current study focuses only on 26 course-level practices. The interviews were analyzed by thematic analysis (Braun, Clarke, 2006) using NVivo 12 to perform the coding. A coding scheme was developed using a mix of both inductive and deductive approaches (Fereday \& Muir-Cochrane 2006) from an extensive literature review during the first year of the project and by coding the transcripts.

This was done in a 3-stage process: First, literature was shared between the coders to start analyzing the transcripts, which the three codes then coded. Each coder looked for insights in the transcripts and developed their own coding schema. Next, we merged the codes from the individual coding schemes with those deducted from the literature. To clarify and align the meaning of the codes, definitions were established and 
fine-tuned in several iterations resulted in a unified coding scheme. Lastly, to establish sufficient consensus between the coders, three interviews were coded by all the coders and the codes' definitions were finalized.
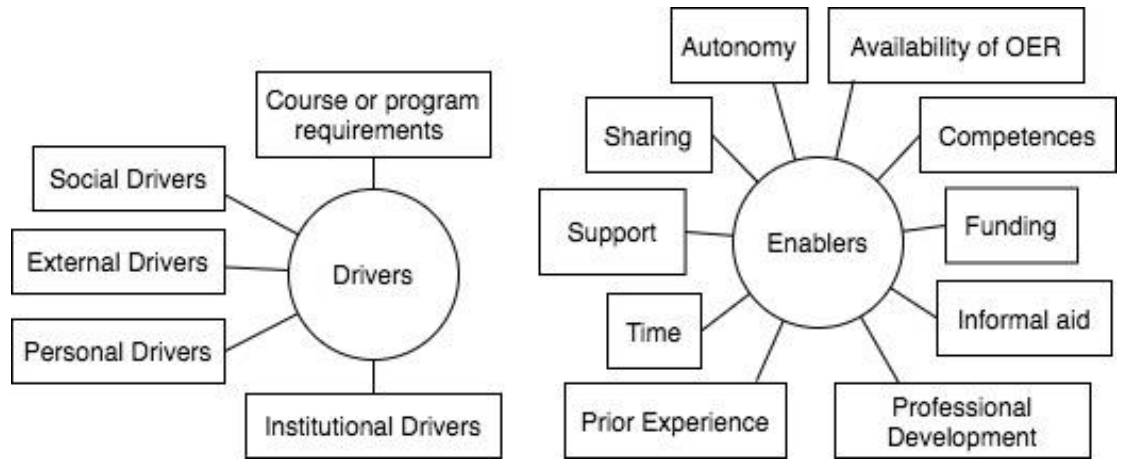

Figure 1. Partial thematic map with drivers and enablers

A thematic map was created for the final unified coding scheme containing 5 main themes: 1) Drivers, 2) Enablers, 3) Challenges and Constraints, 4) Impact of practices and 5) Lifecycle. Our initial analysis presented in this paper contains only the first 2 themes of which a partial thematic map is shown in Figure 1. The three coders applied the unified coding scheme to the 26 interviews divided into three parts.

\section{PRELIMINARY RESULTS}

To answer RQ1, we take a closer look at which drivers and enablers influenced the instructors in this section.

Drivers: Overall, all the instructors (but two) were strongly driven by (a blend of) personal drivers such as catering to students' needs and skills, enhancing learner experiences, or improving their own teaching experiences. A few instructors were also driven by educational research purposes, while others were driven by their interest in using technology and tools. The influence from peers or students also motivated some instructors to adopt BT. Others were driven by course and program requirements like short time frames or evening programs for working professionals. Institutions can also drive instructors to adopt BT by providing university strategies and policies and by offering incentives or opening calls for educational projects. Only two instructors were prompted by external drivers: one was triggered by a call for educational projects outside the university and another worked towards a professional standards framework by a HE regulatory body.

Enablers: Most of the instructors reported needing and receiving technological help, especially at the first run of their course using BT tools. There was a rather limited demand for pedagogical assistance. Some instructors were enabled by peers sharing resources (experiences or material) in structured or unstructured activities and getting help even informally from the academic community. Another major enabler was funding - in the form of grants, investments in MOOCs, staff scholarships, or paying for temporary personnel, etc. Professional development and Open Education Resources also enabled some BT practices. As interviewees typically had a high degree of autonomy over the mode of course delivery, only few mentioned this as an enabler.

Evolution of Drivers and Enablers: For several instructors, the drivers and enablers for a first run of a course were different from those for subsequent iterations of a course answering RQ2. Furthermore, depending on the lifecycle of the course, a code could be a driver or an enabler revealing a dynamic nature. For example, some viewed funding as a driver but for others, it was only an enabler.

\section{DISCUSSION AND CONCLUSION}

Preliminary analysis revealed the dynamic nature of drivers and enablers. A code could both be used as a driver or an enabler depending on the lifecycle (iteration) of the course, the competences of the instructors and diverse contexts. Moreover, drivers or enablers for an initial iteration of a course are constantly evolving 
in future runs. Further analysis is needed to understand their relationships and interactions, and the diverse contexts affecting them. Other findings include advice to work in didactic teams to implement BL, impacts of approaches, challenges and constraints faced for adoption or continued use and possible workarounds. A limitation of this study is that only instructor perspectives on BT are considered. While students' perspectives are just as important when discussing the impact of BT education, there were several limitations in collecting information from a representative sample of students across multiple disciplines, in different European universities. Future research could focus on students' perspectives and comparing them to those of the instructors'.

The pandemic undoubtedly was a forceful driver for instructors to teach online or adopting BT but it is important to understand differences in employing truly optimal and purposeful BT versus teaching traditional content (a)synchronously online or via hybrid methods. Institutions have also stepped up their response, increasing their support in several ways. In a post-pandemic context, due to student needs, institutions may demand more on-campus instruction, thereby inciting instructors to return to their previous ways of teaching without the use of online modes, and instructors may not be able to fully reap the benefits of their investments in online teaching during the pandemic. To this end, our research can give insights into BT adoption and provide HE institutions with necessary insights to promote and support the creation and continued use of successful, sustainable practices.

\section{ACKNOWLEDGEMENT}

The data for this research was collected as a part of the EMBED project. This research would not have been possible without the collaboration of the EMBED partners who each conducted four to six interviews in their respective universities. We would also like to express our sincere gratitude to the numerous interviewees for their time and the information and insights they shared. Finally, we thank the European Association of Distance Teaching Universities (EADTU) for chairing, and the EU for funding the project.

\section{REFERENCES}

Boelens, R., De Wever, B., \& Voet, M. 2017. Four key challenges to the design of blended learning: a systematic literature review. Educational Research Review, Vol. 22, pp 1-18.

Bingimlas, K., A., 2009. Barriers to successful Integration of ICT in teaching and learning environments: a review of the literature. Eurasia Journal of Mathematics, Science and Tech Ed, Vol. 5, No. 3, pp. 235-245.

Braun, V., Clarke, V., 2006. Using Thematic Analysis in Psychology. Qualitative Research in Psychology. Vol. 3, No.2, pp. 77-101.

Castro, R., 2019. Blended learning in higher education: Trends \& capabilities. Educ \& Information Technology, Vol. 24, No.4, pp.2523-2546.

Dziuban, C., et al, 2018. Blended learning: The new normal and emerging technologies. International Journal of Educational Technology in Higher Education, pp. 1-16.

Dziuban, C., Shea P., and Moskal, P., 2020. A Question of Blended Learning: Treatment Effect or Boundary Object? Educause Review. Why IT matters to Higher Education.

Fereday, J. and Muir-Cochrane, E., 2006. Demonstrating Rigor Using Thematic Analysis: A Hybrid Approach of Inductive and Deductive Coding and Theme Development. International Journal of Qualitative Methods, pp. 80-92.

Goeman, K., et al, 2021. Development of a Maturity Model for Blended Education: A Delphi Study. International Journal on E-Learning, Vol. 20, No.3, pp. 229-258.

Ibrahim, M.M., Nat, M., 2019. Blended learning motivation model for instructors in higher education institutions. International Journal of Education Technology in Higher Education, Vol. 16, No.12.

King, S. E., \& Cerrone Arnold, K., 2012. Blended learning environments in higher education: A case study of how professors make it happen. Mid-Western Educational Researcher, Vol.25, No.1, pp. 44-59.

Lam, J. 2015. A Thematic Analysis of the Blended Learning Experiences of Undergraduate Students in Hong Kong. CITE2014, Hong Kong. Vol. 494, pp. 215-224.

Laurillard, D., 2014. Thinking about blended learning A paper for the Thinkers in Residence programme. pp. 1-26. 
Lawrence, J., E., \& Tar U., A., 2018. Factors that influence teachers' adoption and integration of ICT in teaching/learning process. Educational Media International, Vol. 55, No.1, 00 79-105.

Lu, O. H., et al, 2018. Applying learning analytics for the early prediction of Students' academic performance in blended learning. Journal of Educational Technology \& Society, Vol. 21, No.2, pp 220-232.

Marshall, S., 2010. A Quality Framework for Continuous Improvement of E-Learning: The E-Learning Maturity Model. Journal of Distance Education, Vol. 24, No. 1, pp. 143-166.

Mercader \& Gairin, 2020. University teachers' perception of barriers to the use of digital technologies: the importance of the academic discipline. International Journal of Educational Technology in HE, Vol 17, No. 4.

Müller, C., \& Mildenberger, T, 2021. Facilitating flexible learning by replacing classroom time with an online learning environment: A systematic review of blended learning in higher education. Educational Research Review, Vol. 34.

Noetel, M., et Al, 2021. Video Improves Learning in Higher Education: A Syst Review. Review of Educ Research Vol. 91.

Porter, W. W., \& Graham, C. R., 2016. Institutional drivers and barriers to faculty adoption of blended learning in higher education. British Journal of Educational Technology, Vol. 47, No. 4, pp. 748-762.

Rasheed, R. A., Kamsin, A., \& Abdullah, N. A., 2020. Challenges in the online component of blended learning: A systematic review. Computers and Education, Vol. 144, 103701.

Smith, K., \& Hill, J., 2019. Defining the nature of blended learning through its depiction in current research. Higher Education Research \& Development, Vol. 38, pp. 383-397.

van Valkenburg, W.F. et al, 2020. European Maturity Model for Blended Education. Report published by European Association of Distance Teaching Universities. 